REFERENCES:

[1] Vranken L et all. The Phenotype of Patients with a Recent Fracture: A Literature Survey of the Fracture Liaison Service. Calcif Tissue Int (2017) 101:248-258

[2] Briggs $\mathrm{AM}$ et all. Hospitalisations, admission costs and re-fracture risk related to osteoporosis in Western Australia are substantial: a 10-year review. Aust N Z J Public Health. 2015 Dec;39(6):557-62.

[3] Svedbom A et all. Epidemiology and economic burden of osteoporosis in Switzerland. Arch Osteoporos. 2014;9:187.

[4] Kanis J.A. European Guidance for the diagnosis and management of osteoporosis in postmenopausal women. Osteoporosis Int (2013) 24, 2357.

Disclosure of Interest: None declared

DOI: 10.1136/annrheumdis-2018-eular.7540

\section{AB1391 OBSTACLES FACING EVIDENCE BASED MEDICINE IN PHYSICAL MEDICINE AND REHABILITATION: FROM OPINION AND KNOWLEDGE TO PRACTICE}

M. Babaee, S.A. Raeissadat, S.M. Rayegani, M.H. Bahrami. Physical medicine and rehabilitation research center, Shahid Beheshti university of medical sciences, Tehran, Iran, Islamic Republic of Ireland

Background: Evidence-based medicine (EBM) is a new approach to medicine. Up to now, there have been fewavailable articles about specialists' EBM status, specifically the status of physiatrists in the area of EBM.

Objectives: To determine the present status of physiatrists' attitudes, knowledge and skill in the area of EBM andthe existing obstacles

Methods: The cross-sectional study was performed among physiatrists in Iran. The valid and reliablequestionnaire contained 25 questions in 8 fields including demographic and professional information, point ofview regarding EBM, familiarity with databases, educational history and information about EBM, use ofscientific resources, scientific evidence usage, and the amount of access to resources. Results: One hundred twenty-eight questionnaires were completed (response percentage $52.2 \%$ ). In total, $48.4 \%$ specialists had attended EBM workshops and $89.6 \%$ of people were familiar with medical search engines. Theamount of familiarity with databases was mostly with MEDLINE/PubMed (52.3\%). Respondents mainly had apositive point of view towards EBM. Those who had access to databases at work or somewhere out of home hada more positive attitude $(p=0.002)$. Those who had attended EBM workshops and members of faculty also hadmore positive attitudes ( $\mathrm{p}=0.003$ and $\mathrm{p}=0.01$, respectively). Around $70 \%$ of responders had adequate knowledgeregarding EBM. Physicians, members of faculty and participants who had spent more time on research, reviewedarticles and attended workshops had more knowledge $(p=0.001)$.

Conclusions: Results from our study revealed that although there is a significant number of physiatrists who are familiar with the practicality of EBM, they are still not familiar enough with its concepts and applications.

\section{REFERENCES:}

[1] Raeissadat SA, Samadi B, Rayegani SM, Bahrami MH, Mahmoudi H. Survey of Medical Residents' Attitude Toward Physical Medicine and Rehabilitation. American Journal of Physical Medicine \& Rehabilitation. 2014; 93 (6): 540-7. doi: 10.1097/PHM.0000000000000057. PMID: 24508929.

[2] Raeissadat SA, Bahrami MH, Rayegani SM, Babaee M, Roshan Pajoh R. Attitude, beliefs and knowledge of iranian physiatrists towards Evidence Based Medicine and its barriers. A cross-sectional study. Eur J Phys Rehabil Med. 2016; 52(5): 755-7. PMID: 27164540.

[3] Raeissadat SA, Bahrami MH, Rayegani SM, Hassanabadi H, Babaee M, Najafi $\mathrm{S}$, et al. Obstacles facing evidence based medicine in physical medicine and rehabilitation: from opinion and knowledge to practice. Electronic Physician. 2017;9(11).

Disclosure of Interest: None declared

DOI: 10.1136/annrheumdis-2018-eular.7008

\section{AB1392 EFFECT OF UNIVERSITY STRUCTURE ON MEDICAL STUDENTS' KNOWLEDGE DURING EXAM PREPARATION}

\section{R. Sengewein, R. Brinks, G. Pongratz. POLIKLINIK FÜR RHEUMATOLOGIE,} UNIKLINIK DÜSSELDORF, Düsseldorf, Germany

Background: In 2016 the German Society of Rheumatology found out that only seven faculties out of 37 could be classified as an independent rheumatological teaching unit. Amount of lecture hours and type varied largely between universities and was usually the most in universities with academic freedom. Besides the lack of lectures in rheumatology, all students have to pass a medical state examination ("Staatsexamen"), which is carried out by the IMPP ("Institut fü Medizinische und Pharmazeutische Prüfungsfragen"). The written exam consists of 320 Multiple-Choice IMPP-Questions with only one correct answer out of five possible choices. Approximately five to ten questions, varying from exam to exam, also contain rheumatological content. After each exam questions are published and used by younger students for exam preparation. The e-Learning platform "Amboss" is frequently used by medical students for this reason in Germany. Objectives: To investigate the effect of university structure on correct answering former IMPP-Questions during exam preparation.

Methods: We analysed former IMPP-Questions answered by students over a four-year period recorded on "Amboss"Oct. 2012 _ . Oct. 2016 First time answered questions with rheumatological content from students during exam preparation were identified and extracted from the total record. Students with only a single or very few questions answered were not considered as being in exam preparation and excluded. A sensitivity analysis was done after exclusion. Students from independent (Group A) and non-independent (Group B) medical faculties were divided into two groups and investigated for the rate of correct answering IMPP-Questions. Statistical Analysis was done with the Statistical Software R (The R-Foundation for Statistical Computing; Version 3.4.1)

Results: A total of 176 questions with rheumatological content were identified 32.166 students answered those questions or a subset of these (in total 2.610.217 questions). After excluding students not being in exam preparation 14.739 students were left, answering those questions 2.148.801 times. On an average $68,3 \%$ of the questions were answered correctly. The sensitivity analysis did not show a significant difference. 3330 students from Group A answered 495.614 questions, on an average 69,4\% correct. 11.409 students from Group B answered 1.963.066 questions, on an average $68 \%$ correct. The difference between both groups was significant $(p<0.01)$.

Conclusions: Students from independent faculties answered more questions correct than from non-independent faculties. The difference was significant, but taking into account the few questions asked in the real exam the difference would have no relevance.

Disclosure of Interest: None declared

DOI: 10.1136/annrheumdis-2018-eular.5388

\section{AB1393 EFFECT OF AN EDUCATIONAL INTERVENTION BASED ON CLINICAL SIMULATION IN THE DIAGNOSIS OF RHEUMATOID ARTHRITIS IN LATIN AMERICAN NON- RHEUMATOLOGISTS PHYSICIANS}

S.A. Mora Alfonso ${ }^{1,2}$, D.G. Fernández Ávila ${ }^{2,3} .{ }^{1}$ Rheumatology, Universidad de la Sabana; ${ }^{2}$ Rheumatology, Sociedad para la Investigación, atención y educación en enfermedades reumáticas INVEDER SAS; ${ }^{3}$ Pontificia Universidad Javeriana Hospital Universitario San Ignacio. Bogotá, Colombia, Bogotá, Colombia

Background: Previously our group demonstrated the effectiveness of an educational intervention based on clinical simulation to improve the diagnostic approach to RA (Rheumatoid Arthritis) ${ }^{(1)}$ so we wanted to apply this same principle in the learning of RA among a group of Latin American non-Rheumatologists

Objectives: This paper wants to quantify the rate of improvement in the diagnosis of Rheumatoid Arthritis (RA) among a group of Latin American non-Rheumatologists (general practitioners, internists, physiatrists, orthopedists, neurosurgeons dermatologists) who received an educational intervention based on clinical simulation.

Methods: Observational study before and after

Results: 286 Latin American non-rheumatologists physicians recieved an educational intervention based on clinical simulation. The topic of this educational intervention was based on Rheumatoid Arthritis. They revieved a workshop that includes clinical simulation models of 5 hands and each hand, had various semiological findings of RA (synovitis, pannus, joint deformities). The workshop lasted 5 hours and it was divided into two parts: the first was about the clinical approach of joint pain and relevant aspects of RA. The second part focused on clinical cases applied to clinical simulation models, applying the knowledge acquired during the theoretical phase. Participants made a several stations where they could appreciate for periods of 20 min each simulator and improve their visual and tactile sensitivity in each semiologic findings for the diagnosis of RA. The participants filled out a pre and post test, which included 6 (six) clinical cases with simulators and photographs of hands of patients with suspected RA. 286 non-rheumatologists (general practitioners, internists, physiatrists, orthopedists, neurosurgeons, dermatologists) from 3 Latin American countries (Colombia, Costa Rica and Dominican Republic) participated in the study, $71 \%$ women, average age 40,3 years (SD 7,5 years). Non-rheumatologists physicians obtained an improvement in the correc diagnosis of RA of $45,6 \%$ (the correct diagnosis increased from $44,5 \%$ to $90,1 \%$ ). The total number of exams requested in the cases presented decreased significantly, from an average of 7 to 3 exams requested by each clinical case presented. $95 \%$ of participants would recommend to other colleagues to make this 
workshop. $97 \%$ believe that this educational intervention will improve the diagnostic approach to patients with suspected RA.

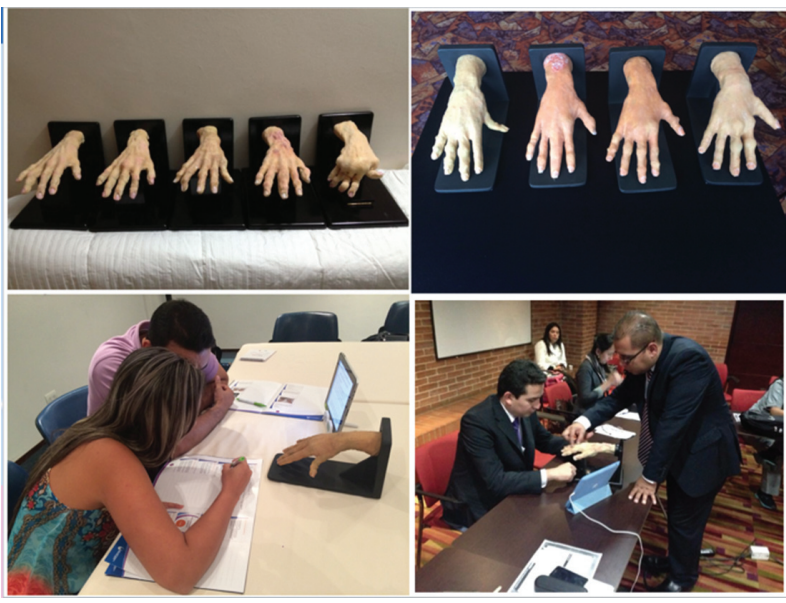

Abstract AB1393 - Figure 1

Conclusions: The present research is a pioneer and innovator in the field of rheumatology education. We have shown the usefulness of clinical simulation by an improvement in the diagnostic sensitivity towards the diagnosis of RA, highlighting the semiology as a key element at the time of making the diagnosis. A significant decrease in the total number of exams requested for each of the clinical cases analysed was documented, which can have a positive effect on costs for the national health systems.

REFERENCE:

[1] Fernández-Ávila DG, Ruiz ÁJ, Gil F, Mora SA, Tobar C, Gutiérrez JM, Rosselli D. The effect of an educational intervention, based on clinical simulation, on the diagnosis of rheumatoid arthritis and osteoarthritis.Musculoskeletal Care. 2017;1-5.DOI: 10.1002/msc.1228

Disclosure of Interest: None declared

DOI: 10.1136/annrheumdis-2018-eular.6124

\section{AB1394 DEVELOPMENT OF A SERIES OF SIMULATORS AND DESIGN OF A COURSE BASED ON CLINICAL SIMULATION, FOR TEACHING DIAGNOSTIC APPROACH TO PATIENTS WITH JOINT PAIN AND SUSPECTED RHEUMATIC DISEASES}

S.A. Mora Alfonso ${ }^{1,2}$, D.G. Fernández Ávila ${ }^{2,3}$, on behalf of Sociedad para la Investigación, atención y educación en enfermedades reumáticas INVEDER SAS. ${ }^{1}$ Rheumatology, Universidad de la Sabana; ${ }^{2}$ Rheumatology, Sociedad para la Investigación, atención y educación en enfermedades reumáticas INVEDER SAS ${ }^{3}$ Pontificia Universidad Javeriana - Hospital Universitario San Ignacio. Bogotá, Colombia, Bogotá, Colombia

Background: The teaching of clinical approaches to patients with RA (Rheumatoid Arthritis) and SpA (Spondyloarthritis) requires both a practical and a theoretical component, and there are difficulties in having real patients for teaching Previously our group has shown the use of clinical simulation in rheumatology, an area in which it had not been used. We demonstrated the effectiveness of an educational intervention based on clinical simulation to improve the diagnostic approach to RA1. Thus, the idea emerged to apply clinical simulation in the field of RA and SpA teaching. An exhaustive search of the scientific literature through May 2017 revealed no works on clinical simulation for rheumatic diseases. The simulation models recieved a patent for intellectual property and utility for education, with a 10-year protection.

Methods: Design and installation a life-sized mannequin and separate anatomical parts (five hands, six fingers, three feets) with a set of semiological findings for SpA and RA

Results: We have designed unique simulation models -a life-sized mannequin and separate anatomical parts (five hands, six fingers, three feets) with a set of semiological findings for SpA and RA. Each simulator (artificial hands, finger or feet) has natural size and was made of epoxy resin. The simulators ligaments, muscles and support tissues were made of silicone rubber, and the simulator was covered by polyurethane skin on an acrylic support. Each hand, feet or finger has various semiological findings of $\mathrm{SpA}$ and RA (synovitis, pannus, enthesitis, dactylitis, joint deformities, classical findings of psoriatic nails and psoriatic plaques) made from materials that generated textures very similar to those found in real patients. Learning is transferred from interacting with the models by using the sense of touch to feel and perceive how the clinical manifestations of the diseases are. The workshops comprise a six-stage rotation where the anatomical models are accompanied by a brief video describing a clinical case. After viewing the video participants interacts with the models to understand and recognise each of the clinical features of SpA and RA, as if in a real patient. Whereas in regular work shops where knowledge is transfer through a keynote speaker and visual images, this one is a total learning by the experience of touching and feeling.

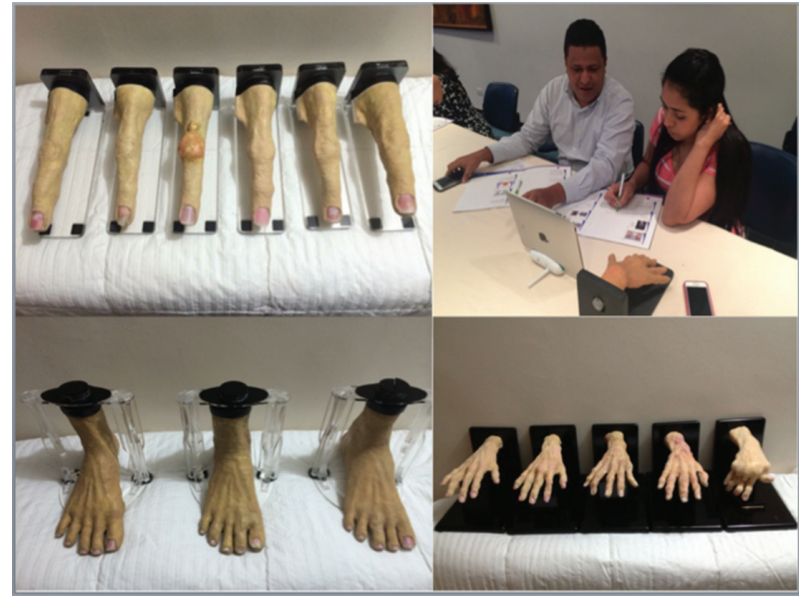

Abstract AB1394 - Figure 1

Conclusions: The present research is a pioneer and innovator in the rheumatology education. In this vein, we hope that this research is the first in the context of a new way of teaching rheumatology, educational process and eventually will have a global projection that allows the creation of a course for early diagnosis and initial treatment of rheumatic diseases, similar to what is currently done in cardiology with ACLS and in trauma with ATLS

\section{REFERENCE:}

[1] Fernández-Ávila DG, Ruiz ÁJ, Gil F, Mora SA, Tobar C, Gutiérrez JM Rosselli D.The effect of an educational intervention, based on clinical simulation, on the diagnosis of rheumatoid arthritis and osteoarthritis.Musculoskeletal Care. 2017;1-5.DOI: 10.1002/msc.1228

Disclosure of Interest: None declared DOI: 10.1136/annrheumdis-2018-eular.6149

\section{AB1395 EFFECT OF AN EDUCATIONAL INTERVENTION BASED ON CLINICAL SIMULATION IN THE DIAGNOSIS OF SPONDYLOARTHRITIS (SPA) FROM GENERAL PRACTITIONERS, A STUDY BEFORE AND AFTER}

S.A. Mora Alfonso ${ }^{1,2}$, D.G. Fernández Ávila ${ }^{2,3}$, on behalf of Sociedad para la Investigación, atención y educación en enfermedades reumáticas INVEDER SAS. ${ }^{1}$ Rheumatology, Universidad de la Sabana; ${ }^{2}$ Rheumatology, Sociedad para la Investigación, atención y educación en enfermedades reumáticas INVEDER SAS; ${ }^{3}$ Pontificia Universidad Javeriana - Hospital Universitario San Ignacio. Bogotá, Colombia, Bogotá, Colombia

Background: Previously our group has shown the use of clinical simulation in rheumatology. We demonstrated the effectiveness of an educational intervention based on clinical simulation to improve the diagnostic approach to RA1, so we wanted to apply this same principle in the learning of SpA (Spondyloarthritis).

Objectives: This paper wants to quantify the rate of improvement in the diagnosis of Spondyloarthritis $(\mathrm{SpA})$ among a group of general practitioners who receive an educational intervention based on clinical simulation.

Methods: Intervention study before and after

Results: 102 general practitioners received an educational intervention based on clinical simulation. The topic of this educational intervention was Spondyloarthritis $(\mathrm{SpA})$. A workshop that includes clinical simulation models of feet, fingers and a mannequin created for this purpose was created, based on the strategy of problem-based learning. The workshop lasted 5 hours, it was divided into two parts: the first was about the of the clinical approach of joint pain and lumbar pain diag nosis and relevant aspects of SpA. In this first part, besides the theoretical support 